\title{
Pelatihan Mendeley Untuk Penulisan Sitasi Karya Ilmiah Bagi Mahasiswa Universitas Islam Kadiri
}

\author{
Ahmad Idris ${ }^{1}$, Suseno Hendratmoko², Dina Ayu Lestari ${ }^{3}$, Ahmad Agus Tri Mulyono ${ }^{3}$ \\ 1,2,3,4 Universitas Islam Kadiri \\ email : ahmadidris@uniska-kediri.ac.id ${ }^{1}$, susenohendratmoko@uniska-kediri.ac.id², dinaayyu15@gmail.com², \\ ahmadagustrimulyono@gmail.com ${ }^{3}$
}

\begin{abstract}
The purpose of the service activity is to provide training on the use of Mendeley Manager references to Kadiri Islamic University students in writing thesis. Based on the author's observations, it is still found that many students at the time of writing their thesis or scientific work still use citations and bibliography manually which are feared to be prone to errors in their preparation. The training was held face-to-face with a limited number of 15 students taking place in the classrooms of the Kadiri Islamic University campus. The result of the activity is the increasing ability of students in using the Mendeley application and being able to make citations and bibliography using the reference manager. It is hoped that such training activities will be carried out regularly for students.
\end{abstract}

Keywords: mendeley, thesis, student, reference, citation.

\begin{abstract}
Abstrak
Tujuan kegiatan pengabdian adalah memberikan pelatihan penggunaan referensi manager mendeley kepada mahasiswa Universitas Islam Kadiri dalam penulisan skripsi. Berdasarkan pengamatan penulis masih banyak ditemukan mahasiswa pada saat penulisan skripsi atau karya ilmiah masih menggunakan kutipan dan daftar pustaka secara manual yang dikhawatirkan rawan kesalahan dalam penyusunannya. Pelatihan diadakan secara tatap muka terbatas dengan jumlah peserta 15 orang mahasiswa bertempat di ruang kelas kampus Universitas Islam Kadiri. Hasil kegiatan adalah meningkatnya kemampuan mahasiswa dalam penggunaan aplikasi mendeley dan mampu membuat kutipan dan daftar pustaka menggunakan referensi manager. Harapannya kegiatan pelatihan seperti ini rutin dilaksanakan kepada mahasiswa.
\end{abstract}

Kata Kunci: mendeley, skripsi, mahasiswa, referensi, kutipan.

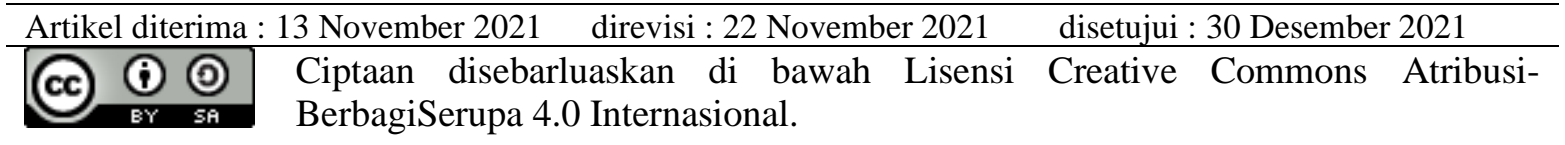




\section{Pendahuluan}

Skripsi merupakan tugas akhir mahasiswa yang mengambil jenjang strata satu di perguruan tinggi (Suprihati \& Fitria, 2021). Skripsi adalah karya ilmiah yang disusun berdasarkan kaidah-kaidah ilmiah berdasarkan prosedur penelitian yang telah ditentukan (Sahla et al., 2019). Sehingga skripsi merupakan karya ilmiah yang wajib diselesaikan oleh mahasiswa (Pramiastuti et al., 2020). Tujuan penulisan skripsi sendiri untuk menghasilkan sebuah karya ilmiah berdasarkan hasil penelitian mahasiswa dan menguji sejauh mana penguasaan keilmuan yang diperoleh selama masa perkuliahan dalam bentuk tulisan (Perdana, 2020; Ma'ruf \& Fitria, 2021).

Penulisan skripsi yang berkualitas merupakan hal yang harusnya menjadi perhatian bagi mahasiswa dan dosen (Kurniadi, 2017). Pengetahuan mengenai kutipan, parafrase, dan plagiarisme menjadi modal penting dalam penyusunan karya ilmiah (Dewi \& Diani, 2021). Mahasiswa diharapkan menyusun skripsi sesuai pedoman penulisan skripsi masing-masing perguruan tinggi dan memanfaatkan aplikasiaplikasi yang dapat membantu dalam penyelesaian skripsi. Salah satu aplikasi referensi manager yang dapat digunakan adalah mendeley. Mendeley tersedia dalam 2 (dua) versi yaitu versi desktop dan versi web.

Dalam penyusunan skripsi diperlukan kutipan/sitasi untuk mendukung dan memperkuat tulisan peneliti di dalam skripsi tersebut. Kutipan/sitasi harus mencantumkan sumber dan tahun (Windarto et al., 2018; Hastari, 2021). Macam kutipan ada dua yaitu kutipan langsung dan kutipan tidak langsung. Kutipan langsung adalah kutipan yang sama dengan sumber aslinya sedangkan kutipan tidak langsung adalah kutipan yang merupakan gubahan dari penulis tanpa mengurangi makna yang dikutip. Setiap sumber kutipan yang ditulis harus dicantumkan di dalam daftar pustaka skripsi. Menurut Dewi \& Diani (2021) masih ditemukan fakta rendahnya penulisan kutipan dalam pembuatan karya ilmiah.

Daftar pustaka atau bibliografi adalah bagian akhir dari sebuah skripsi yang menerangkan sumber referensi yang digunakan oleh mahasiswa (Ngibad, 2020). Daftar pustaka disusun menggunakan gaya (style) yang sudah ditentukan pada buku panduan penulisan skripsi Fakultas Ekonomi Universitas Islam Kadiri yaitu menggunakan APA (American Psychological Association $7^{\text {th }}$ Edition). Dengan daftar pustaka yang lengkap akan menerangkan darimana teori dan sumber kutipan yang digunakan (Mardin et al., 2020).

Hasil pengamatan penulis terhadap beberapa mahasiswa program studi manajemen Universitas Islam Kadiri berkaitan penulisan sumber kutipan dan daftar pustaka selama melakukan bimbingan skripsi masih ditemukan penulisan kutipan atau sitasi secara manual begitupula penulisan daftar pustaka secara manual. Hal ini tentunya dapat menimbulkan ketidaksempurnaan dalam penyusunan skripsi dikarenakan rawan kesalahan.

Tujuan pelatihan Mendeley bagi mahasiswa Universitas Islam Kadiri yaitu: 1) Melatih mahasiswa dalam membuat kutipan dan daftar pustaka menggunakan referensi manager; 2) Meningkatkan kemampuan menulis mahasiswa dengan kutipan yang benar dan daftar pustaka; dan 3) Meningkatkan kualitas skripsi mahasiswa.

Berdasarkan persoalan di atas, maka penulis tertarik untuk memberikan pelatihan kepada mahasiswa tentang penggunaan aplikasi mendeley dalam penyusunan skripsi. Luaran yang diharapkan dari kegiatan ini adalah mahasiswa dapat menggunakan aplikasi mendeley dalam penyelesaian tugas akhir berupa skripsi. Sehingga kualitas skripsi yang dihasilkan menjadi lebih baik.

\section{Metode Pelaksanaan}

Kegiatan pelatihan dilaksanakan secara tatap muka terbatas. Pelatihan dilaksanakan di gedung Ulil Albab kampus 
Universitas Islam Kadiri pada hari Senin, tanggal 15 November 2021. Peserta pelatihan adalah mahasiswa dengan jumlah 15 orang. Kegiatan pelatihan ini dibagi menjadi dua sesi yaitu sesi pertama instalasi mendeley dan sesi kedua penggunaan mendeley.

\section{Hasil Dan Pembahasan}

Sesi pertama yaitu instalasi mendeley. Tujuan sesi pertama ini adalah mahasiswa mampu menginstal aplikasi mendeley pada laptop mahasiswa sehingga dapat digunakan kapanpun dan dimanapun mahasiswa berada. Berikut merupakan gambar-gambar tutorial instalasi sebagai berikut:

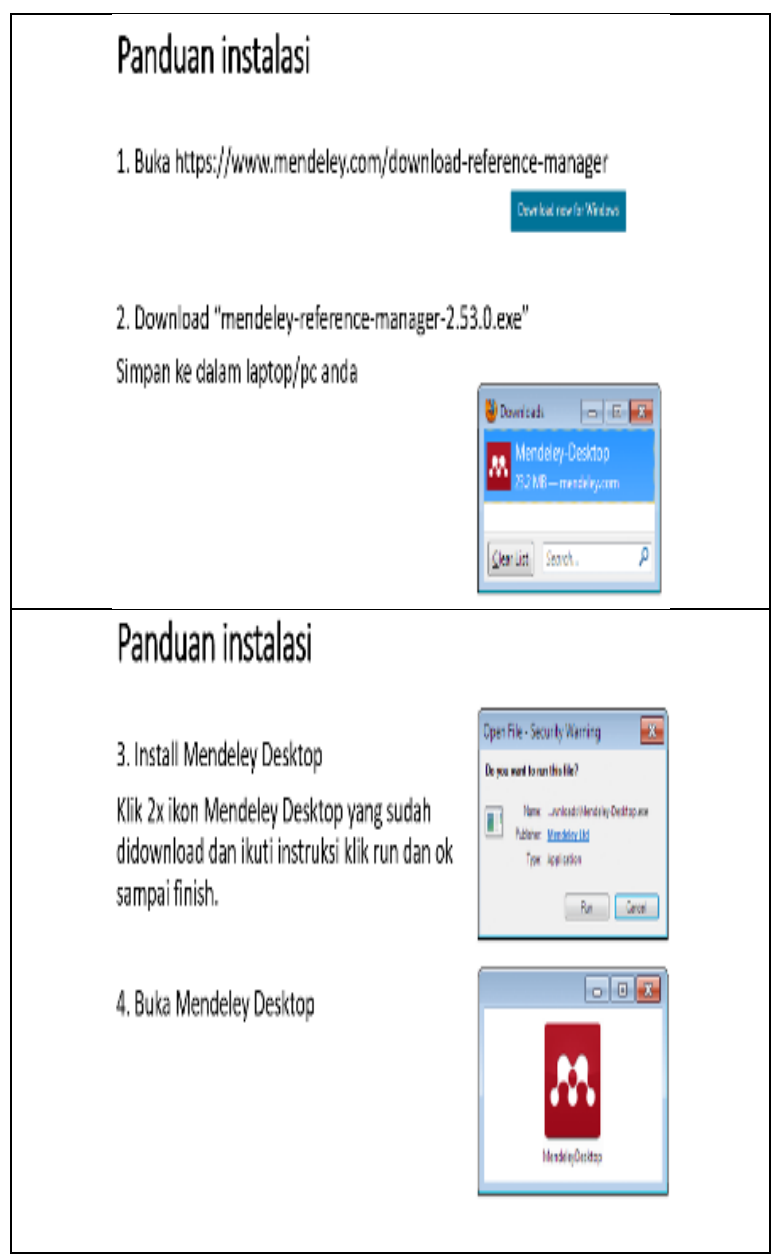

Gambar 1. Langkah pertama instalasi

Pada gambar 1 di atas menginstruksikan mahasiswa untuk mengunduh installer mendeley pada laman www.mendeley.com sampai proses insta- lasi selesai setelah itu dilanjutkan pada gambar 2 di bawah. Mahasiswa perlu menyiapkan email yang aktif dalam proses pendaftaran akun mendeley.

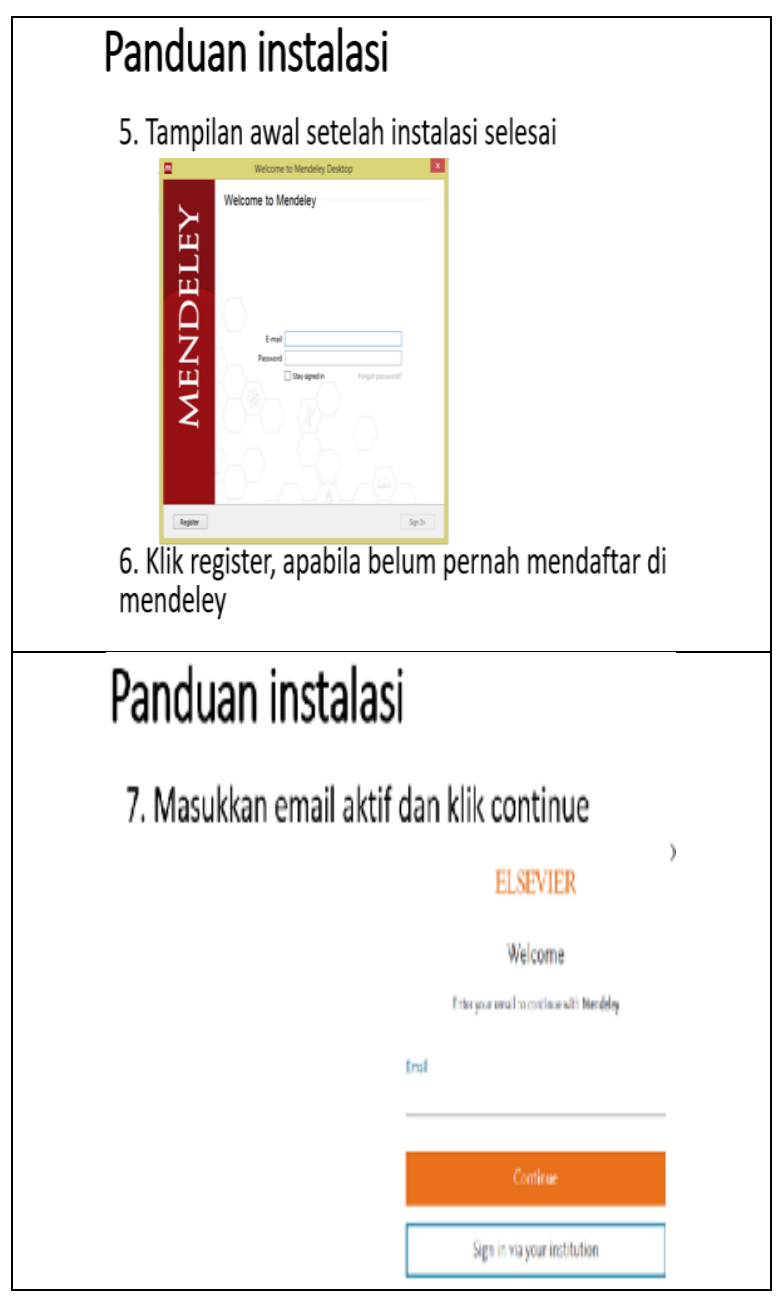

Gambar 2. Langkah kedua pendaftaran akun

\section{Panduan instalasi}

8. Masukkan Given name, Family name dan password

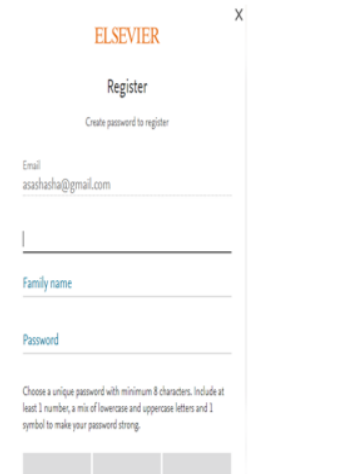

Gambar 3. Langkah ketiga aktivasi email 
Pada gambar 3 di atas mahasiswa perlu memasukkan family name (nama panggilan) dan password mendeley. Kemudian membuka email dan menyelesaikan registrasi mendeley.

\section{Panduan instalasi}

9. Setelah berhasil cek inbox email yang didaftarkan pada mendeley untuk menyelesaikan registrasi

10. Tampilan awal berhasil masuk ke dalam mendeley

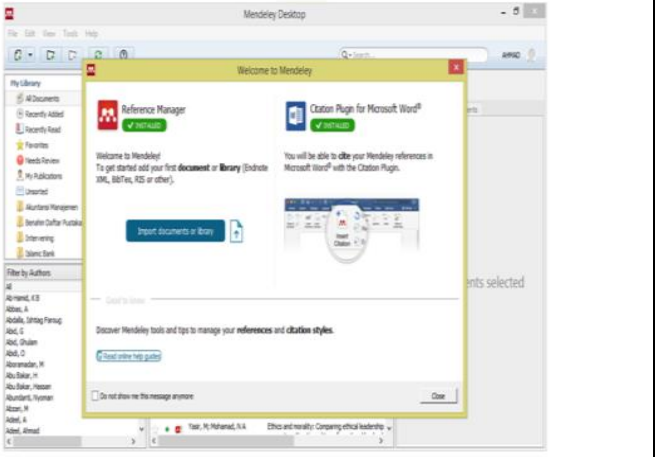

Gambar 4. Tampilan Bagian Dalam Mendeley

Pada gambar 4 menunjukkan tampilan bagian dalam aplikasi mendeley setelah berhasil memasukkan username dan password.

\section{Panduan instalasi}

11. Terakhir install "Citation Plugin for Microsoft Word" Pada menu Tools klik Install MS Word Plugin

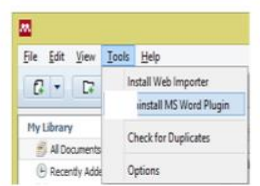

12. Buka microsoft word pada menu REFERENCES sudah terinstall plugin mendeley

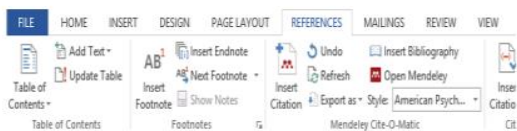

Gambar 5. Langkah keempat Instal MS Word Plugin

Pada gambar 5 tahap terakhir yaitu menginstal MS Word Plugin pada Mendeley Desktop dengan cara klik menu
Tools $\rightarrow$ Install MS Word Plugin. Kemudian buka microsoft word dan lihat pada menu Reference sudah terinstal Ms Word Plugin untuk Mendeley.

Setelah sesi pertama yaitu instalasi mendeley selesai, maka dilanjutkan pada sesi kedua yaitu penggunaan mendeley. Pertama, mahasiswa harus membuka aplikasi mendeley dengan klik icon Mendeley pada laptop. Kemudian login menggunakan email dan password saat registrasi. Kedua, mahasiswa juga membuka aplikasi microsoft word untuk latihan penulisan kutipan dan daftar pustaka menggunakan mendeley.

Pada gambar 6. mahasiswa diminta membuat folder agar database mendeley terorganisir. Caranya pada menu My Library klik Create Folder dan berikan nama pada folder baru yang dibuat. Dicontohkan membuat folder skripsi sebagai tempat menyimpan data-data buku, jurnal, dan lain-lain yang digunakan dalam penulisan skripsi.

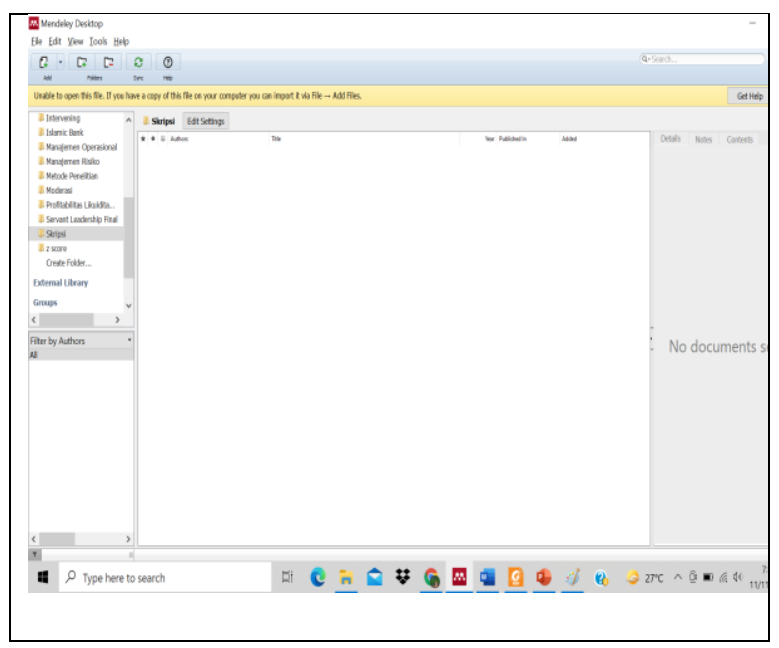

Gambar 6. Pembuatan Folder

Mahasiswa melakukan praktik memasukkan data berupa metadata buku dan pdf jurnal. Penulis sudah menyiapkan beberapa buku tentang metode penelitian sebagai simulasi memasukkan metadata ke dalam mendeley. Untuk memasukkan metadata buku secara manual langkahlangkah sebagai berikut:

- Klik File $\rightarrow$ Add Entry Manually

- Type: Book 
- Title: Prosedur Penelitian : Suatu Pendekatan Praktik

- Authors: Arikunto, Suharsimi

- Year: 2013

- Publisher: Jakarta: Rineka Cipta

- ISBN: 9789795189985

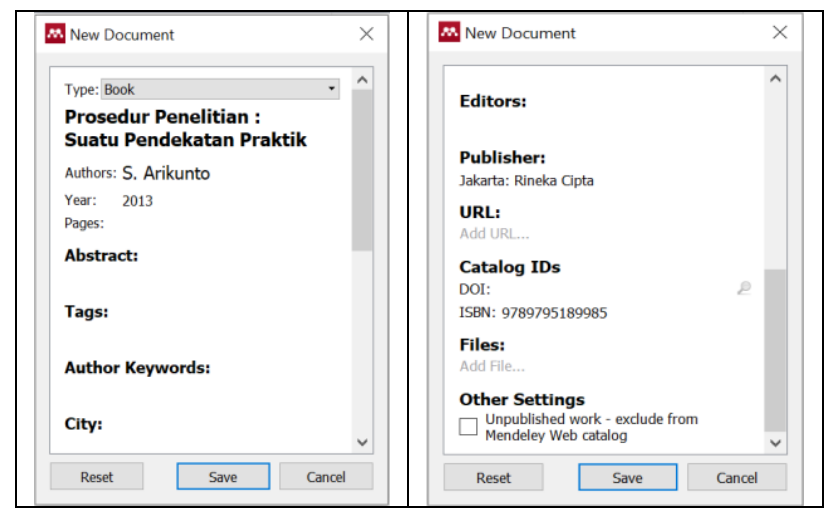

Gambar 7. Memasukkan dataset buku

Untuk memasukkan jurnal bisa langsung dari mendrag file pdf ke folder Skripsi atau halaman tengah mendeley seperti gambar 8 di bawah.

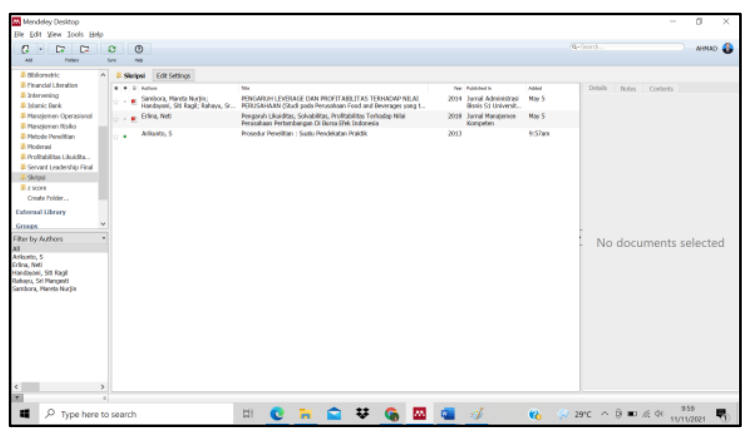

Gambar 8. Tampilan mendeley

Berikutnya adalah praktik membuat kutipan pada microsoft word. Mahasiswa membuka aplikasi microsoft word dan menyiapkan kalimat yang akan dikutip, langkah-langkah memunculkan sumber kutipan pada microsoft word sebagai berikut:

- Klik References

- Klik Insert Citation

- Klik Go To Mendeley

- Klik metadata yang akan dimasukkan sumbernya

- Klik simbol cite (")
Untuk memunculkan daftar pustaka langkah-langkah sebagai berikut:

- Klik References

- Klik Insert Bibliography

Hasil seperti gambar 8 di bawah dengan gaya (style) APA $7^{\text {th }}$ edition.

Metode penelitian adalah cara yang digunakan oleh peneliti dalam mengumpulkan satuan penelitiannya (Arikunto, 2013).

Dalam hal ini Debt To Aset Ratio nilki kemempun dalan mis). semua hutangnya pada saat perusahaan dilikuidasi (Erlina, 2018).

Variabel bebas yang berpegaruh dominan terhadap harga saham dalam penelitian ini adalah EPS. Variabel (Sambora et al., 2014)

Daftar Pustak

Arikunto, S. (2013). Prosedur Penelitian : Suatu Pendekatan Praktik. Jakarta: Rineka Cipta.

Erlina, N. (2018). Pengaruh Likuiditas, Solvabilitas, Profitabilitas Terhadap Nilai Perusahaan Pertambangan Di Bursa Efek Indonesia. Jurnal Manajemen Kompeten, 1(1), 13. https://doi.org/10.51877/mnjm.v1i1.17

Sambora, M. N., Handayani, S. R., \& Rahayu, S. M. (2014). PENGARUH LEVERAGE DAN PRofitABILTAS (Studi pada Perusahaan Food and Beverages yang terdaftar

Gambar 9. Praktik mendeley pada microsoft word

Dokumentasi kegiatan pelatihan pada gambar 10 di bawah.

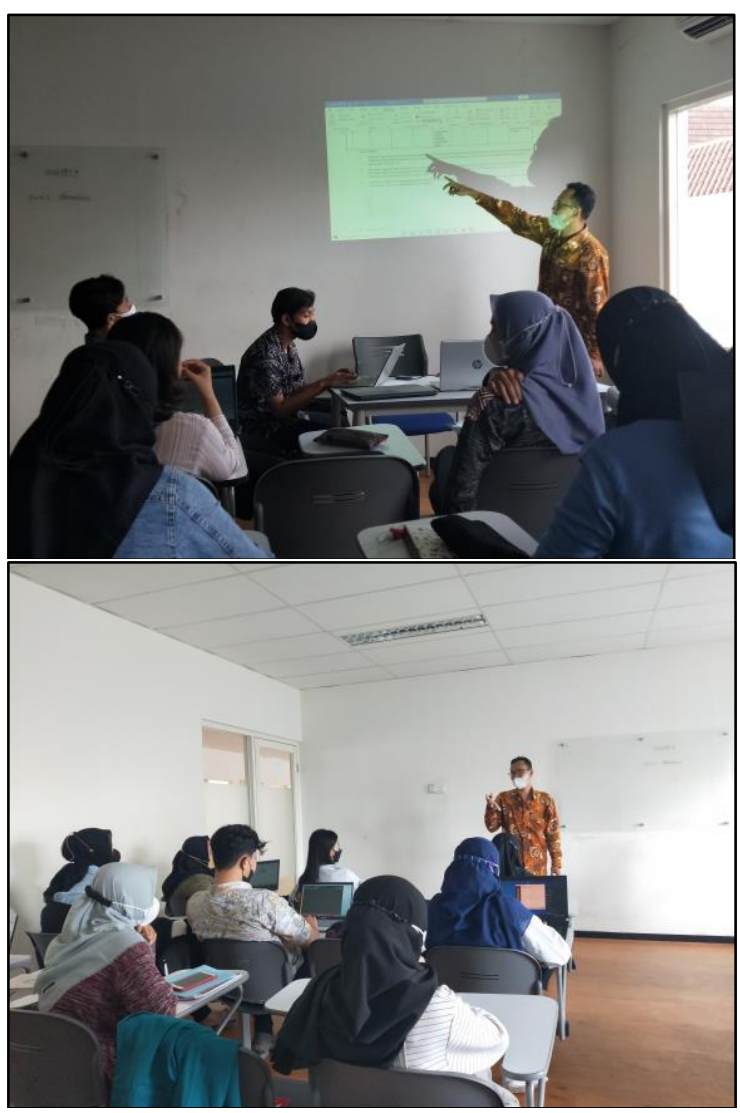

Gambar 10. Dokumentasi Pelatihan 


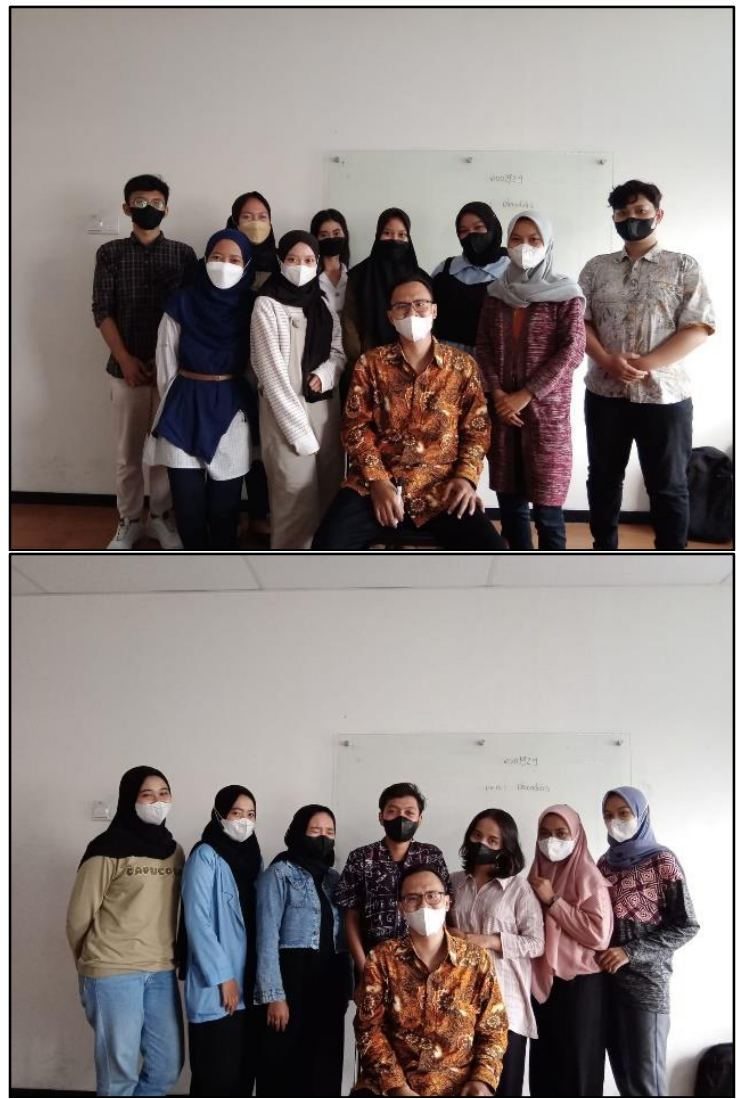

Gambar 11. Foto Bersama

\section{Simpulan}

\section{Penutup}

Sebagaimana tujuan kegiatan yang sudah dijelaskan di awal. Kesimpulan dari kegiatan ini memberikan kemampuan menggunakan aplikasi mendeley sebagai referensi manager dalam penulisan skripsi dan meningkatkan kemampuan cara mengutip dan menuliskan daftar pustaka menggunakan referensi manager. Kegiatan berjalan dengan lancar.

\section{Saran}

Kegiatan pelatihan mendeley hendaknya lebih sering dilaksanakan kepada mahasiswa agar meningkatkan kemampuan teknis dalam menyusun karya ilmiah menggunakan referensi manager yang ada. Untuk kegiatan pelatihan kedepan yaitu parafrase dan kiat-kiat agar terhindar dari plagiarisme. Selain itu diharapkan mahasiswa juga semakin banyak membaca, karena dengan banyak membaca akan meningkatkan kemampuan menulis.

\section{Ucapan Terimakasih}

Penulis sampaikan terima kasih kepada Ibu Dekan Fakultas Ekonomi Universitas Islam Kadiri yang telah memberikan ijin terlaksananya kegiatan pengabdian ini.

\section{Daftar Pustaka}

Dewi, L. S., \& Diani, W. R. (2021). Pelatihan Teknik Pembuatab Kutipan Bagi Guru Dan Pengawas Di Kabupaten Magelang. ABDIPRAJA (Jurnal Pengabdian Kepada Masyarakat), 2(2), 228-231.

Hastari, R. C. (2021). Pelatihan Penelusuran Referensi dan Pencegahan Plagiasi Pada Kegiatan Diklat Dasar Karya Tulis Ilmiah. Cendekia: Jurnal Pengabdian Masyarakat, $\quad 3(1), \quad 18$. https://doi.org/10.32503/cendekia.v3i 1.1582

Kurniadi, F. (2017). Penulisan Karya Tulis Ilmiah Mahasiswa Dengan Media Aplikasi Pengolah Kata. AKSIS: Jurnal Pendidikan Bahasa Dan Sastra Indonesia, 1(2), 267-277. https://doi.org/10.21009/aksis.010208

Ma'ruf, M. H., \& Fitria, T. N. (2021). Pelatihan Penulisan Artikel Ilmiah dari Skripsi dan Tesis Untuk Mahasiswa Serta Cara Publikasinya ke Jurnal Nasional. Jurnal ABDAYA : Pengabdian Dan Pemberdayaan Masyarakat, 1(1), 6-12.

Mardin, H., Baharuddin, B., \& Nane, L. (2020). Pelatihan Cara Menulis Sitasi dan Daftar Pustaka Jurnal Format Apa Style Menggunakan Aplikasi Mendeley. Jurnal Abdidas, 1(3), 137143.

https://doi.org/10.31004/abdidas.v1i3. 37

Ngibad, K. (2020). Pelatihan Mendeley Secara Online Bagi Mahasiswa Fikes Umaha Di Masa Pandemi Covid-19. Pengabdian Dan Pemberdayaan 
Nusantara, 2(1), 110-116.

Perdana, F. J. (2020). Pelatihan Membuat Daftar Pustaka Otomatis Dengan Aplikasi Mendeley Desktop Bagi Mahasiswa Dalam Persiapan Penyusunan Tugas Akhir. Dimasejati: Jurnal Pengabdian Kepada Masyarakat, 2(1), 75. https://doi.org/10.24235/dimasejati.v $2 \mathrm{i} 1.6652$

Pramiastuti, O., Rejeki, D. S., \& Pratiwi, A. (2020). Pengenalan Dan Pelatihan Sitasi Karya Ilmiah Menggunakan Aplikasi Mendeley. Jurnal Abdimas Bhakti Indonesia, 1(1), 24-30.

Sahla, W. A., Mukhlisah, N., Julkawait, \& Irwansyah, R. (2019). IbM-Pelatihan Teknik Penulisan Parafrase Untuk Skripsi Mahasiswa Sebagai Upaya Menghindari Plagiarisme. Jurnal Impact: Implementation and Action, 1(2), 162-168.

Suprihati, \& Fitria, T. N. (2021). Pelatihan Penulisan Karya Ilmiah (Tugas Akhir dan Skripsi) Bagi Mahasiswa D3 dan S1 di Provinsi Jawa dan Luar Jawa. Jurnal Pengabdian Masyarakat: TRISNA MAS, 1(1), 1-9. https://doi.org/10.47232/jptm.v1i1.91

Windarto, A. P., Hartama, D., \& Wanto, A. (2018). Pelatihan Pemanfaatan Mendeley Desktop Sebagai Program Istimewa Untuk Akademisi Dalam Membuat Citasi Karya Ilmiah. Aksiologiya: Jurnal Pengabdian Kepada Masyarakat, 2(2), 145-150. 